\title{
INGV strong-motion data web-portal: a focus on the Emilia seismic sequence of May-June 2012
}

\author{
Marco Massa , Sara Lovati, Dario Sudati, Gianlorenzo Franceschina, Emiliano Russo, Rodolfo Puglia, \\ Gabriele Ameri, Lucia Luzi, Francesca Pacor, Paolo Augliera
}

Istituto Nazionale di Geofisica e Vulcanologia, Sezione di Milano/Pavia, Milano, Italy

\author{
Article history \\ Received July 20, 2012; accepted August 23, 2012. \\ Subject classification: \\ Strong-motion data, Web portal, Data processing.
}

\section{Introduction}

In Italy, strong-motion monitoring was started in 1972 by different Institutions, although mainly through Ente Nazionale per l'Energia Elettrica (ENEL; Italian National Electricity Company) and Dipartimento della Protezione Civile (DPC; Italian Department of Civil Protection), with different purposes. These included permanent accelerometric monitoring and temporary monitoring during seismic sequences or before permanent installation. Today, the National Accelerometric Network (RAN; Rete Accelerometrica Nazionale) [Gorini et al. 2010, Zambonelli et al. 2011] is operated by the DPC and consists of 464 digital stations. These are distributed throughout the whole national territory, with a prevalence for areas of major seismicity.

In 2006, the INGV began strong-motion monitoring, by installing 22 accelerometric stations in northern Italy (RAIS; Rete Accelerometrica Italia Settentrionale; Accelerometric Network of Northern Italy; http: / / rais.mi.ingv.it/). In 2008, the monitoring was extended to a national scale: this effort led to the installation of 105 accelerometers, collocated with the velocimetric sensors, in selected Rete Sismica Nazionale (RSN; National Seismic Network) sites [Amato and Mele 2008] that are managed by the Centro Nazionale Terremoti (CNT; National Earthquake Centre). Overall, the 127 strongmotion stations that form the INGV Italian strong-motion network homogeneously cover the whole Italian territory.

The progress achieved in Italy in the field of strong-motion monitoring and strong-motion data archiving and dissemination was illustrated in a recently published special issue of the Bulletin of Earthquake Engineering [Luzi et al. 2010]. The strong-motion data recorded by the RAN have been distributed and are available on request to the DPC and to the Italian Accelerometric Archive (ITACA), as the Italian strong-motion database (http: / / itaca.mi.ingv.it/) [Pacor et al. 2011a], which has been updated with records to 2009. The INGV strong-motion data are archived in real-time and dis- tributed through the European Integrated Data Archive (EIDA; http: / / eida.rm.ingv.it/) web portal.

Recently, an INGV working group developed the first version of a web portal with the aim of archiving, processing and distributing accelerometric data recorded by permanent and temporary INGV stations. This web portal (www.mi. ingv.it/ISMD/; Figure 1, top panel) is composed of two main modules: the former is known as the INGV Strong Motion Data (ISMD, www.mi.ingv.it/ISMD/ismd.html/; Figure 1, bottom left panel) and has as its main scope the analyse and distribution in quasi-real time (a few hours after event occurrence) of the uncorrected accelerometric data, and the related metadata obtained after an automatic processing procedure. This latter, known as the Dynamic Archive (DYNA, http: / / dyna.mi.ingv.it/DYNA-archive/; Figure 1, bottom right panel) is a dynamic database where manually postprocessed accelerometric waveforms are provided, together with their metadata. Both of these archives are designed and structured in such a way that their compilations and updating will be almost completely automatic.

At the end of May 2012, a first prototype of the ISMD module was published, providing the uncorrected strongmotion data recorded by the INGV stations for the main events of the Emilia seismic sequence [Massa et al. 2012].

\section{The INGV strong-motion data: quasi real-time automatic strong-motion analyses}

The ISMD module (www.mi.ingv.it/ISMD/ismd.html/) is distributed in quasi-real-time (a few hours after an earthquake occurrence), as the INGV uncorrected accelerometric data and related strong-motion parameters, as obtained after automatic processing. Possible delays in data publishing depend on the number of requests made by users to EIDA.

ISMD now includes about 2,000 uncorrected strong-motion waveforms that relate to the events with $4.0 \leq \mathrm{M}_{\mathrm{L}} \leq 5.9$ that occurred in the central part of the Padano-Emiliana 


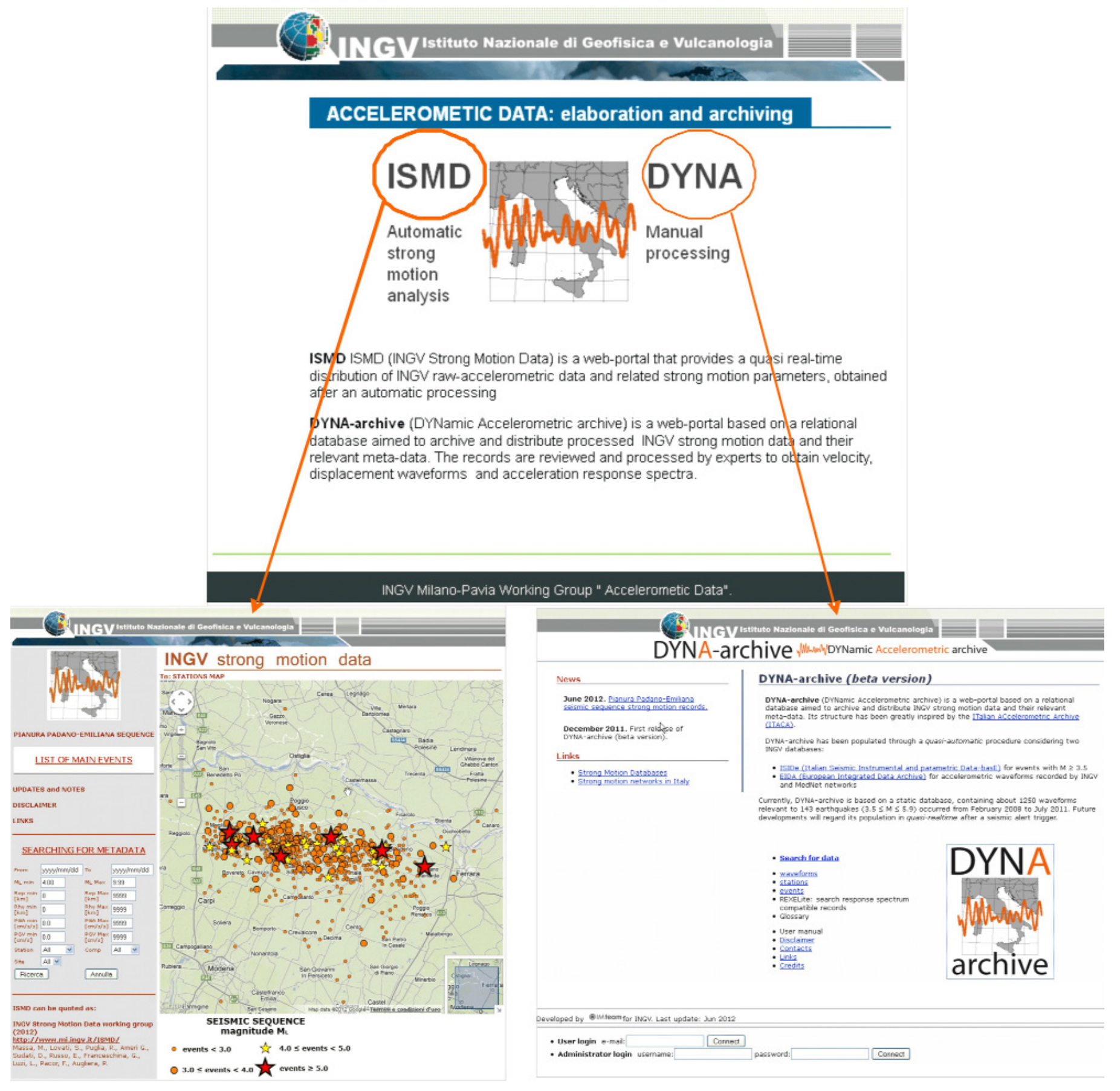

Figure 1. INGV strong-motion data web portal: home page (top panel); ISMD home-page (bottom left); DYNA home page (bottom right).

Plain (northern Italy) from May 20 to June 12 (Figure 2, left panel). The data were recorded by all of the INGV permanent and temporary strong-motion stations that were installed in northern Italy, including from the RSN [Amato and Mele 2008], the RAIS (http: / / rais.mi.ingv.it/) [Augliera et al. 2011] and the INGV temporary network [Moretti et al. 2012, Bordoni et al. 2012, this volume], with latitudes $\geq 43.5^{\circ} \mathrm{N}$. The locations and local magnitudes, $\mathrm{M}_{\mathrm{L}}$, that are reported on the web site were provided by the CNT of INGV (http:// cnt.rm.ingv.it/).

An automatic procedure has the main aim to publish on the web site both the metadata (provided after automatic data processing) and downloadable waveforms in uncor- rected ASCII format. Starting from the origin time of each earthquake (provided by the CNT), the procedure automatically downloads 5 min of Mini-SEED continuous signal from EIDA (http://eida.rm.ingv.it/). Soon after the data download, the automatic data processing starts. It includes: (i) baseline correction, to have a zero-mean signal and to remove any linear trend, computed with a least square method; (ii) tapering of the signal through a $1 \%$ cosine function at the beginning and at the end of each selected window; (iii) application of a 4th order Butterworth band-pass acausal [Boore and Akkar 2003] filter to remove the high-frequency and low-frequency noise. The filter cut-off thresholds are automatically selected on the basis of the event magnitude (i.e., 

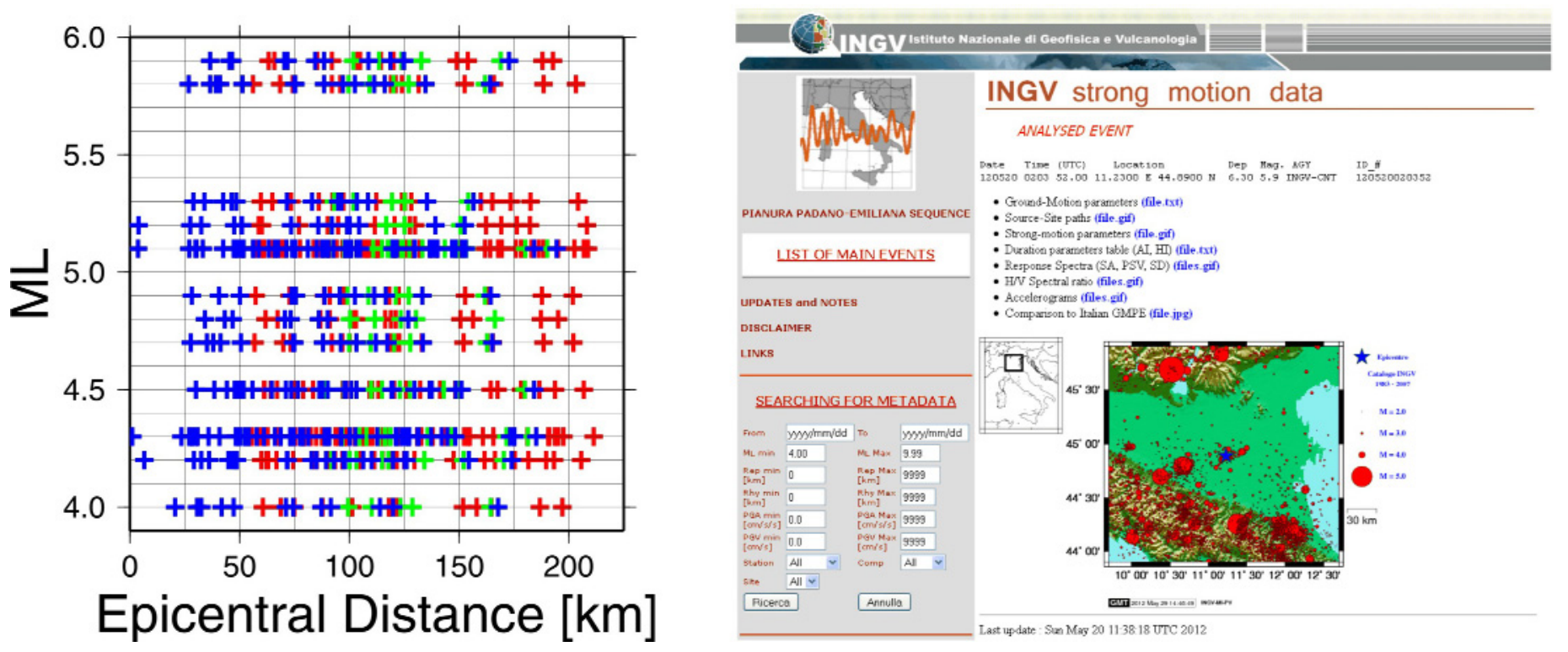

Figure 2. Left: ISMD dataset collected during the Emilia 2012 seismic sequence and now available from the INGV strong-motion data web portal. Red, EC8 A soil category; green, EC8 B soil category; blue, EC8 C soil category [CEN 2003]. Right: web-page automatically generated a few hours after the May 20, 2012, M 5.9 mainshock (see 'Last update: Sun May 20 11:38:18 UTC 2012').

$0.1-40 \mathrm{~Hz}$ for $\mathrm{M}_{\mathrm{L}} \geq 5.5 ; 0.2-35 \mathrm{~Hz}$ for $4.5 \leq \mathrm{M}_{\mathrm{L}}<5.5 ; 0.3-35 \mathrm{~Hz}$ for $3.5 \leq \mathrm{M}_{\mathrm{L}}<4.5$ ).

Given the characteristic of the digital stations, no instrumental correction is applied. Starting from the automatically processed data, velocity waveforms are obtained by integration of the acceleration traces. Peak ground acceleration (PGA), peak ground velocity (PGV) and 5\%-damped acceleration response spectra (SA) for periods up to $4 \mathrm{~s}$ are calculated. Note that for events with magnitudes $<4.5$, the SA should be only considered in the frequency range defined by the low-pass and high-pass filters.

The automatic system also provides 5\%-damped pseudo-velocity response spectra, 5\%-damped displacement response spectra, Arias intensities (Ia) [Arias 1970] and Housner intensities (Ih) [Housner 1952]. For each recording station, the horizontal-to-vertical spectral ratios (HVSRs) are automatically calculated considering $5 \mathrm{~s}$ and $10 \mathrm{~s}$ of signal selected in correspondence with the more energetic portions of the seismograms. At the end, for each analyzed event, the automatic procedure generates an ad-hoc web page (see Figure 2, right panel, for the May 20, 2012, $\mathrm{M}_{\mathrm{L}} 5.9$ mainshock) that shows the results in terms of static tables (text files), including PGA, PGV, Ia, Ih and SA (at periods of $0.3 \mathrm{~s}$, $1.0 \mathrm{~s}, 3.0 \mathrm{~s}$, as used for shake-map calculations) and generic plots (e.g., location of recording stations, HVSRs, response spectra, accelerograms).

For the events with $M_{L}>5.0$, the comparison between the recorded PGAs and Italian Ground Motion Prediction Equations [Bindi et al. 2011] is shown. For each analysed earthquake, the strong-motion data are downloadable in ASCII format: following the standards proposed by ITACA, the ASCII files are composed of 43 header lines followed by acceleration data in $\mathrm{cm} / \mathrm{s}^{2}$.
Moreover, the dynamic output files can be generated in Table format, e.g., specifying the time window, ground-motion parameters (PGA and PGV), magnitudes, epicentral and hypocentral distance ranges, and Eurocode8 site category [CEN 2003]. At present, the preliminary site classification of the INGV stations is based on a lithological map at a national scale $(1: 100,000)$, which was developed by the INGV as part of the ShakeMap project in Italy [Michelini et al. 2008], as shown in Figure 2 of Di Capua et al. [2011].

\section{The DYNA archive}

The DYNA module (http://dyna.mi.ingvit/DYNAarchive/) is a beta-version of the dynamic accelerometric database that is aimed at archiving and distributing the INGV strong-motion data and their relevant metadata. It is based on a relational database and its structure was greatly inspired by ITACA (http:/ / itaca.mi.ingv.it/ItacaNet/).

The first release of DYNA contained about 1,250 waveforms related to 143 earthquakes $\left(3.5 \leq \mathrm{M}_{\mathrm{L}} \leq 5.9\right)$ that occurred from February 2008 to July 2011. It was populated through a quasi-automatic procedure that considered two INGV databases: 1) the Italian Seismic Instrumental and Parametric database (ISIDe, http:/ / iside.rm.ingv.it/iside) for events with $\mathrm{M}_{\mathrm{L}} \geq 3.5 ; 2$ ) EIDA (http:/ / eida.rm.ingv.it/), for accelerometric waveforms recorded by the INGV networks (i.e., the RSN, RAIS, MedNet; http:/ / mednet.rm.ingv.it/rcmt.php).

In June 2012, the strong-motion data relative to six events with magnitudes $>5$ (Table 1 ) that occurred during the Emilia sequence were made available on DYNA, together with their metadata.

To publish the waveforms recorded for each event, the download of SEED volumes (fseed) from EIDA was fully automated, starting from the twitter event alert service of the 


\begin{tabular}{|c|c|c|c|c|c|c|}
\hline $\begin{array}{l}\text { Origin Time } \\
\text { (UTC) }\end{array}$ & $\begin{array}{l}\text { Longitude } \\
\quad\left({ }^{\circ} \mathrm{E}\right)\end{array}$ & $\begin{array}{l}\text { Latitude } \\
\qquad\left({ }^{\circ} \mathbf{N}\right)\end{array}$ & $\begin{array}{l}\text { Depth } \\
{[\mathrm{m}]}\end{array}$ & $\mathbf{M}_{\mathrm{L}}$ & $\begin{array}{l}\text { ISMD \# } \\
\text { stations }\end{array}$ & $\begin{array}{l}\text { DYNA \# } \\
\text { stations }\end{array}$ \\
\hline 120520020352 & 11.230 & 44.890 & 6.3 & 5.9 & 30 & $52(50)$ \\
\hline 120520020630 & 11.189 & 44.886 & 7.7 & 4.8 & 26 & l \\
\hline 120520020731 & 11.370 & 44.863 & 5.0 & 5.1 & 30 & $30(20)$ \\
\hline 120520021146 & 11.370 & 44.840 & 7.8 & 4.3 & 31 & l \\
\hline 120520021242 & 11.220 & 44.820 & 20.4 & 4.3 & 29 & l \\
\hline 120520030250 & 11.100 & 44.860 & 10.0 & 4.9 & 30 & / \\
\hline 120520091321 & 11.241 & 44.879 & 3.1 & 4.2 & 28 & I \\
\hline 120520131802 & 11.490 & 44.831 & 4.7 & 5.1 & 28 & $51(39)$ \\
\hline 120520173714 & 11.380 & 44.880 & 3.2 & 4.5 & 31 & I \\
\hline 120523214118 & 11.251 & 44.868 & 4.8 & 4.3 & 32 & I \\
\hline 120527181845 & 11.158 & 44.882 & 4.7 & 4.0 & 31 & l \\
\hline 120529070003 & 11.090 & 44.850 & 10.2 & 5.8 & 34 & $50(49)$ \\
\hline 120529082551 & 10.943 & 44.901 & 3.2 & 4.5 & 35 & I \\
\hline 120529082723 & 11.106 & 44.854 & 10.0 & 4.7 & 34 & I \\
\hline 120529105557 & 11.008 & 44.888 & 6.8 & 5.3 & 33 & $56(42)$ \\
\hline 120529110002 & 10.950 & 44.873 & 11.0 & 4.9 & 34 & l \\
\hline 120529110025 & 10.947 & 44.879 & 5.4 & 5.2 & 35 & l \\
\hline 120531190404 & 10.980 & 44.891 & 8.7 & 4.2 & 32 & / \\
\hline 120603192043 & 10.943 & 44.899 & 9.2 & 5.1 & 36 & $35(33)$ \\
\hline 120612014836 & 10.888 & 44.880 & 10.8 & 4.3 & 27 & I \\
\hline
\end{tabular}

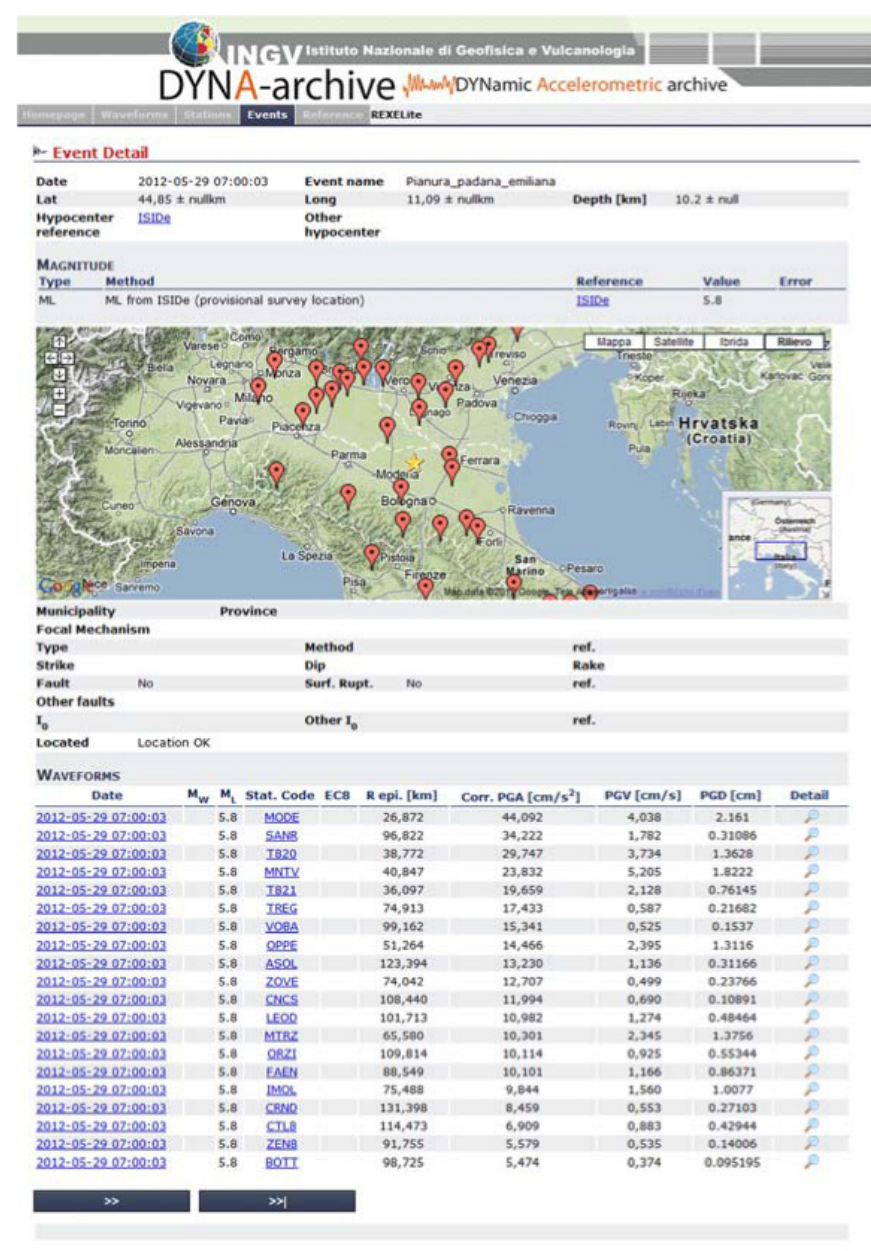

Export in Zip flle

Table 1 (above). Emilia seismic sequence $\left(M_{L} \geq 4\right)$ included in the INGV strong-motion data web portal. Only the events in bold are included in DYNA. The last two columns indicate the number of the recording stations available in ISMD (soon after the occurrence of each earthquake) and the number of those included in DYNA after the manual processing (in brackets, the number of the processed stations). The earthquake locations and magnitudes were provided by the official web site of the National Earthquake Center (CNT) of INGV Rome (preliminary data at http:/ / cnt.rm.ingv.it/).

Figure 3 (left). The May 29, 2012, 07:00:03 event web page, available on http: / / dyna.mi.ingv.it/DYNA-archive/.

INGV (http://twitter.com/ingvterremoti). In this way, we were able to obtain accelerometric waveforms in a time window that generally spanned from some hours after an event occurrence to $24 / 48 \mathrm{~h}$ (depending on the number of requests made to EIDA).

On the other hand, the compilation of the relational database behind the archive is still semi-automatic; however, in the near future, this will be turned into a fully automated procedure. The waveform data and earthquake, station and record information charged in the database after each event are taken from the INGV twitter account (i.e., event: origin time, latitude, longitude, depth, hypocenter reference, magnitude, magnitude type, magnitude reference) and from the SEED volumes (i.e., waveform: acceleration data, time of the first sample; network: code; station: code, name, latitude, longitude, elevation, start/end date; channel: location identifier, latitude, longitude, elevation, depth, start/end date, name and some characteristics of the installed sensor). Figure 3 shows the May 29, 2012, 07:00:03 event page available in the DYNA that lists for each station the epicentral dis- 

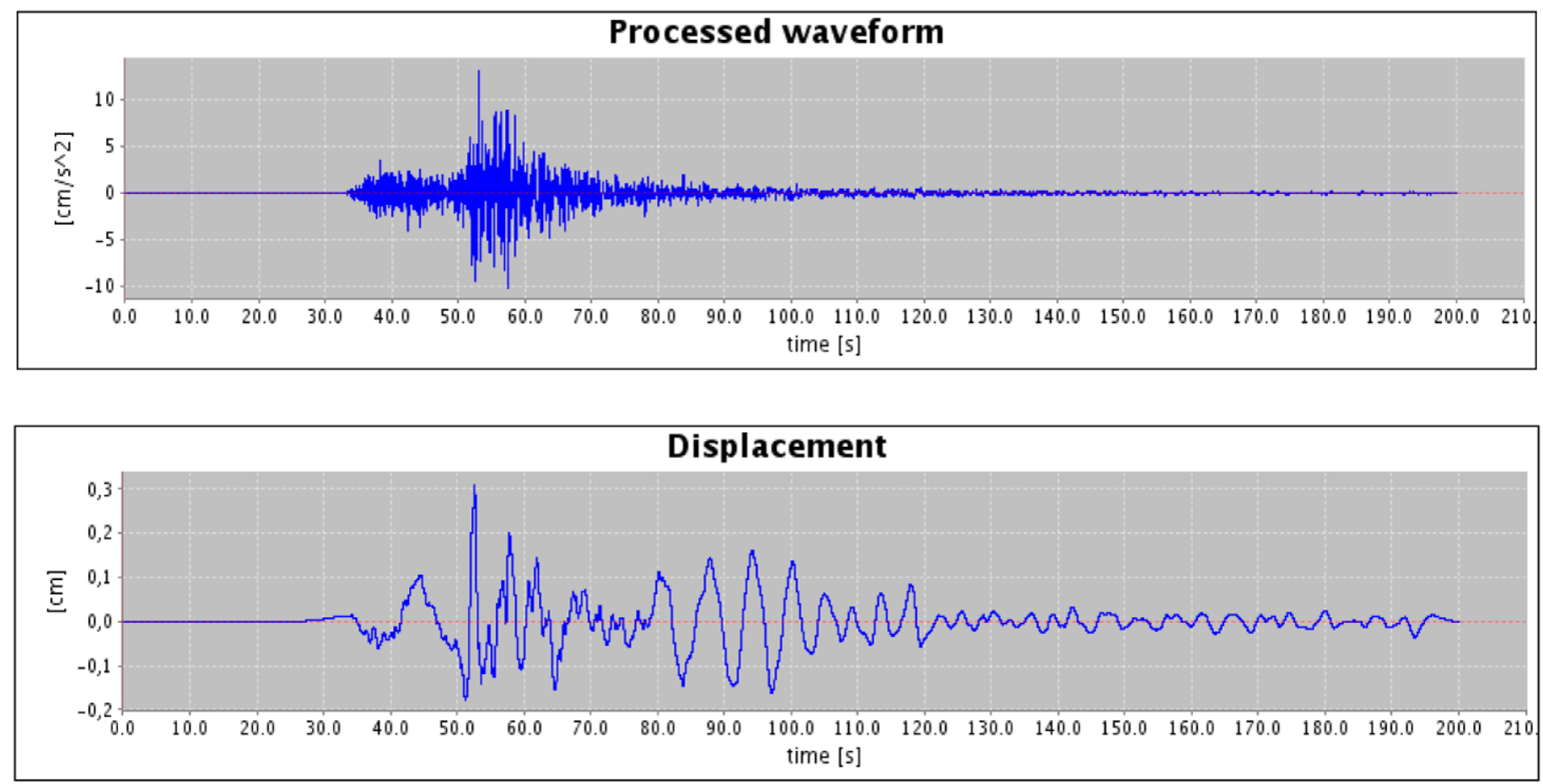

Figure 4. N-S component recorded at ASOL for the May 29, 2012, 07:00:03 event, in terms of the processed acceleration (upper panel) and displacement (bottom panel). These plots were downloaded from http://dyna.mi.ingvit/DYNA-archive/.

tance, and the largest PGA, PGV and peak ground displacement (PGD) among the three components.

The strong-motion data were manually post-processed by expert operators who adopt the procedure used for the ITACA dataset [Paolucci et al. 2011, Pacor et al. 2011b]. For this reason, the corrected data are published on the DYNA web site usually from some days to weeks after the earthquake occurrence (depending on the accuracy that is required, and also considering the features of the analysed waveforms). With respect to the quasi-real-time data published in the ISMD, in some cases, the manual post-processing allows us to download further data from EIDA, also some days after the earthquake origin time (when the EIDA nodes are busy or unavailable).

\section{The Emilia seismic sequence dataset}

The ISMD dataset for the Emilia seismic sequence is composed of 20 events (670 three-component, uncorrected, strong-motion records) with $4.0 \leq \mathrm{M}_{\mathrm{L}} \leq 5.9$ that occurred from May 20, 2012, to June 12, 2012, with epicentral distances up to $215 \mathrm{~km}$. The data are characterized by 29 records with $\mathrm{PGA}>20 \mathrm{~cm} / \mathrm{s}^{2}$, nine of which have PGA $>50 \mathrm{~cm} / \mathrm{s}^{2}$, four as $>100 \mathrm{~cm} / \mathrm{s}^{2}$, and two as $>200 \mathrm{~cm} / \mathrm{s}^{2}$. The maximum PGA $\left(266 \mathrm{~cm} / \mathrm{s}^{2}\right)$ was recorded at the T819 temporary station for the June 3, 2012, $\mathrm{M}_{\mathrm{L}} 5.1$ event (epicentral distance, $3 \mathrm{~km}$ ). For the PGV, just seven records have values $>5 \mathrm{~cm} / \mathrm{s}$, two of which are $>10 \mathrm{~cm} / \mathrm{s}$. Also in this case, the maximum PGV was recorded at T819 for the June 3, 2012, $\mathrm{M}_{\mathrm{L}} 5.1$ event $(28 \mathrm{~cm} / \mathrm{s})$. For the two strongest events, which occurred on May 20, 2012, $\mathrm{M}_{\mathrm{L}} 5.9$ (02:03:52) and May 29, 2012, $\mathrm{M}_{\mathrm{L}} 5.8$ (07:00:03), the maximum PGAs were recorded at the MODE station ( $41 \mathrm{~cm} / \mathrm{s}^{2}$; PGV, $\left.6.3 \mathrm{~cm} / \mathrm{s}\right)$ at $37 \mathrm{~km}$ from the epicenter, and at the T819 station $\left(193 \mathrm{~cm} / \mathrm{s}^{2}\right.$; PGV, $\left.14 \mathrm{~cm} / \mathrm{s}\right)$ at $14 \mathrm{~km}$ from the epicenter, respectively. The DYNA dataset is composed of 233 three-component, manually processed, records, related to 6 events (see Table 1) with $\mathrm{M}_{\mathrm{L}}>5$ that were characterized by epicentral distances of up to $300 \mathrm{~km}$. The waveforms related to the $M_{L} 5.2$ event of May 29, 2012, at 11:00:25 were not taken into account, as the signals overlapped with those that referred to a previous event $\left(M_{L} 4.9\right)$ that occurred at 11:00:02.

Confirming the results obtained by the ISMD automatic procedure, the most significant PGA is $260 \mathrm{~cm} / \mathrm{s}^{2}$, which was recorded on June 3, $2012\left(\mathrm{M}_{\mathrm{L}}\right.$ 5.1) at station T819 (PGV, $28 \mathrm{~cm} / \mathrm{s}$ ). Figure 4 shows an example of the processed waveforms at the ASOL station for the May 29, 2012, 07:00:03 event. Note the surface waves arriving after the S-phase window; i.e., between $80 \mathrm{~s}$ and $100 \mathrm{~s}$ on the displacement trace. This feature is observed for most of the strong-motion data, causing the occurrence of PGDs corresponding to the surface-waves window, probably due to the thick sedimentary cover of the Po Plain.

This type of surface wave is still relatively rare to see on European accelerograms, although it is common, for example, in data from California, USA (e.g., Imperial Valley records from 1979).

\section{Final remarks}

The INGV strong-motion data web portal (formed by the ISMD and DYNA modules) is aimed at collecting and distributing waveforms and the associated metadata to be used for engineering applications and seismological studies. The 


\section{event 20120520020352 ML 5.9}
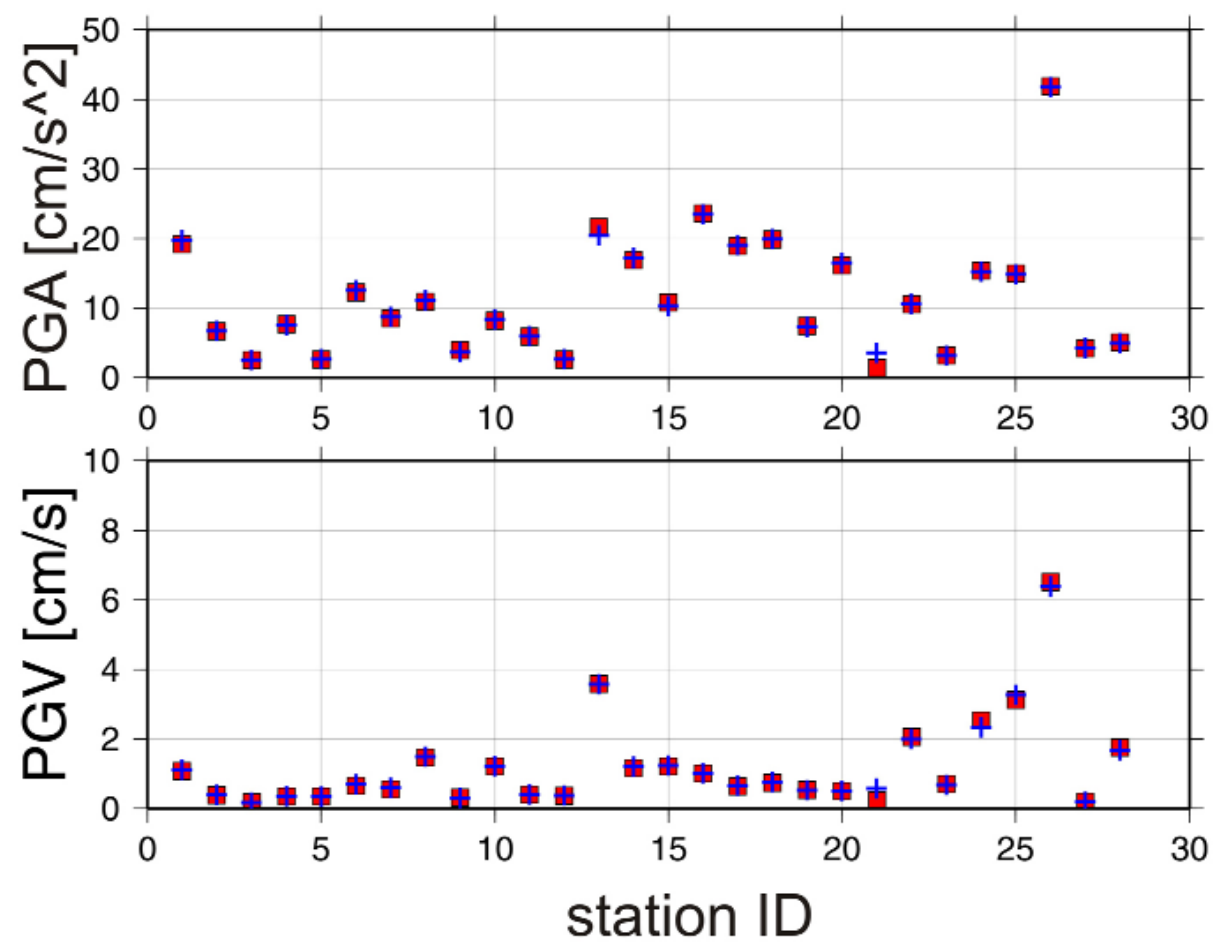

Figure 5. Maxima PGA (top) and PGV (bottom) for the May 20, 2012 (02:03:52 UTM), $M_{L} 5.9$ event. Red squares, values obtained after the manual post processing (DYNA); blue crosses, values obtained after the quasi-real-time data processing (ISMD). Comparisons were performed at common recording stations.

main novelty of the web portal is that the two modules are designed to be compiled and updated automatically, exploiting the automatic systems of the INGV for seismic alert and localization and the EIDA portal for archiving continuous real-time accelerometric waveforms.

The current published version of the ISMD module contains the raw waveforms and relative metadata (i.e., velocity and displacement waveforms and accelerometric response spectra) for events with $M_{L} \geq 4.0$ of the Emilia seismic sequence. The corrected accelerometric data for six events with magnitudes $>5.0$ are instead distributed through the DYNA module.

The strong motion parameters (PGA and PGV) provided by the automatic procedure soon after an earthquake origin time (for the Emilia seismic sequence, usually after a few hours) differ slightly from the values inferred from the corrected data (Figure 5) and represent high-quality information that can be used for quick analyses by a broad variety of users; moreover, the immediate availability of the unprocessed waveforms included in ISMD allows skilful users to perform different data processing on the basis of their specific requirements.

Acknowledgements. The earthquake locations and magnitudes were provided by the official web site of the National Earthquake Centre of the INGV, Rome (preliminary at http:// cnt.rm.ingv.it/, and then revised in the INGV official bulletin) that performs the official monitoring of the Italian territory (H 24). We thank both our INGV colleagues who developed the databases (http:/ / iside.rm.ingv.it/iside; http: / / eida.rm. ingv.it/iside) from which a lot of information can be taken, and our INGV colleagues who were involved in the field activities for the Emilia 2012 seismic sequence. Comments and suggestions from J. Douglas and an anonymous reviewer are strongly acknowledged.

\section{References}

Amato, A., and F. Mele (2008). Performance of the INGV National Seismic Network from 1997 to 2007, Annals of Geophysics, 51 (2/3), 417-431.

Arias, A. (1970). A measure of earthquake intensity, In: R. Hansen (ed.), Seismic Design of Nuclear Power Plants, M.I.T. press, Cambridge.

Augliera, P., M. Massa, E. D'Alema and S. Marzorati (2011). RAIS: a real time strong-motion network in northern Italy, Annals of Geophysics, 54 (1), 23-34.

Bindi, D., F. Pacor, L. Luzi, R. Puglia, M. Massa, G. Ameri and R. Paolucci (2011). Ground motion prediction equations derived from the Italian strong motion database, B. Earthq. Eng., 9, 1899-1920.

Boore, D.M., and S. Akkar (2003). Effect of casual and acausal filters on elastic and inelastic spectra, Earthq. Eng. Struct. D., 32, 1729-1748.

Bordoni, P., R.M. Azzara, F. Cara, R. Cogliano, G. Cultrera, G. Di Giulio, A. Fodarella, G. Milana, S. Pucillo, G. Riccio, A. Rovelli, P. Augliera, L. Luzi, S. Lovati, M. Massa, F. Pacor, R. Puglia and G. Ameri (2012). Preliminary results from EMERSITO, a rapid response network for site-effect studies, Annals of Geophysics, 55 (4); doi:104401 / ag-6153.

CEN (2003). prEN 1998-1- Eurocode 8: design of structures for earthquake resistance. P1: General rules, seismic actions and rules for buildings, Draft 6, Doc CEN/TC250 / 
SC8/N335, Jan 2003, Brussels.

Di Capua, G., G. Lanzo, V. Pessina, S. Peppoloni and G. Scasserra (2011). The recording stations of the Italian strong-motion network: geological information and site classification, B. Earthq. Eng., 9, 1779-1796.

Gorini, A., M. Nicoletti, P. Marsan, R. Bianconi, R. DeNardis, L. Filippi, S. Marcucci, F. Palma and E. Zambonelli (2010). The Italian Strong Motion Network, B. Earthq. Eng., 8, 1075-1090.

Housner, G.W. (1952). Spectrum intensities of strong-motion earthquakes, In: C.M. Feigen (ed.), Proceedings of the Symposium on Earthquake and Blast Effects Structures, University of California, Los Angeles, 21-36.

Luzi, L., P. Augliera and A. Gorini, eds. (2010). Strong Motion Monitoring in Italy, B. Earthq. Eng., Special issue, 8, 1073-1230.

Massa, M., S. Lovati, R. Puglia, G. Ameri, D. Sudati, E. Russo, G. Franceschina, L. Luzi, F. Pacor and P. Augliera (2012). The May 2012 Pianura Padana Emiliana seismic sequence: INGV strong-motion data website, Annals of Geophysics, 55 (3), 507-509; doi:10.4401/ag-5828.

Michelini, A., L. Faenza, V. Lanciani and L. Malagnini (2008). ShakeMap implementation in Italy, Seismol. Res. Lett., 79, 688-697.

Moretti, M., et al. (2012). Rapid response to the earthquake emergency of May 2012 in the Po Plain, northern Italy, Annals of Geophysics, 55 (4); doi:10.4401/ag-6152.

Pacor, F., R. Paolucci, L. Luzi, F. Sabetta, A. Spinelli, A. Gorini, M. Nicoletti, S. Marcucci, L. Filippi and M. Dolce (2011a). Overview of the Italian strong motion database ITACA 1.0, B. Earthq. Eng., 9 (6), 1723-1739; doi:10.1007/ s10518-011-9327-6.

Pacor, F., R. Paolucci, G. Ameri, M. Massa and R. Puglia (2011b). Italian strong motion records in ITACA: overview and record processing, B. Earthq. Eng., 9, 1741-1759.

Paolucci, R., F. Pacor, R. Puglia, G. Ameri, C. Cauzzi and M. Massa (2011). Record processing in ITACA, the new Italian strong-motion database, In: S. Akkar, P. Gulkan and T. van Eck (eds.), Earthquake Data in Engineering Seismology, Geot. Geol. Earthquake, 14, 99-113.

Zambonelli, E., R. De Nardis, L. Filippi, M. Nicoletti and M. Dolce (2011). Performance of the Italian strong-motion network during the 2009, L'Aquila seismic sequence (central Italy), B. Earthq. Eng., 9, 39-65.

\footnotetext{
${ }^{\star}$ Corresponding author: Marco Massa, Istituto Nazionale di Geofisica e Vulcanologia, Sezione di Milano/Pavia, Milano, Italy; email: marco.massa@mi.ingv.it.

(C) 2012 by the Istituto Nazionale di Geofisica e Vulcanologia. All rights reserved.
} 